\title{
A evasão escolar dos discentes em situação de vulnerabilidade socioeconômica e suas relações com o Programa Nacional de Assistência Estudantil - PNAES
}

\section{School dropout of students in situation of socioeconomic vulnerability and its relations with the National Student Assistance Program - Pnaes}

\author{
FRANÇA, Patricia Dayane C. de ${ }^{1}$ \\ BARROS, Geórgia F. \\ SILVA, Simão P. da² \\ MAGALHÃES, Antônio de P. ${ }^{3}$
}

\section{RESUMO}

O objetivo é analisar a evasão escolar dos discentes considerados em situação de vulnerabilidade socioeconômica e suas relações com o Programa Nacional de Assistência Estudantil implementado pelo Instituto Federal de Ciência e Tecnologia do Norte de Minas - Campus Almenara no período de 2012 a 2016, por meio do uso da metodologia de Dados em Painel Linear. Concluiu-se que ser beneficiário de outros programas sociais, morar em local distante do campus e possuir renda per capita inferior a um salário mínimo, aumentam a chance de evasão, o que corrobora a forma de escolha do público-alvo pelo programa. Além disso, verifico-se o potencial do programa em reduzir a evasão escolar em $22 \%$ no período de análise

Palavras chave: evasão escolar, assistência estudantil, instituto federal de ciência e tecnologia

\begin{abstract}
This work was carried out with the objective of analyzing the school dropout of students considered to be in a situation of socioeconomic vulnerability and their relations with the National Student Assistance Program implemented by the Federal Institute of Science and Technology of the North of Minas Campus Almenara in the period from 2012 to 2016 , using the Linear Panel Data methodology. It was concluded that being a beneficiary of other social programs, living far from the campus and having a per capita income below the minimum wage, increases the chance of evasion, which corroborates the program's choice of target audience. In addition, the program's potential to reduce school dropout by $22 \%$ in the period under analysis

Keywords: school dropout, student assistance, instituto federal de ciência e tecnologia
\end{abstract}

\footnotetext{
${ }^{1}$ Mestre em Administração Pública pela Universidade Federal dos vales do Jequitinhonha e Mucuri - UFVJM. Brasil. E-mail: dayanepatricia_cf@hotmail.com

2 Doutorando no Programa de Pós-Graduação em Biocombustíveis da Universidade Federal dos Vales do Jequitinhonha e Mucuri - UFVJM. Professor adjunto na Universidade Federal dos Vales do Jequitinhonha e Mucuri-UFVJM. E-mail: professorsimao@ufvjm.edu.br

${ }^{3}$ Doutor em História da Ciência. Em memória.
} 


\section{Introdução}

Os planos nacionais brasileiros têm concretizado o acesso à educação por meio da expansão das universidades públicas e privadas e ampliação das vagas, sobretudo nas Instituições Federais de Ensino Superior - IFES, buscando a inclusão de alunos pertencentes a camadas de renda menos favorecidas da população.

Entretanto, a permanência ainda é um desafio, considerando as dificuldades financeiras, de deslocamento e de adaptação daqueles que almejam uma formação. Esses desafios, muitas vezes, convergem para a evasão escolar, que é apontada como um tema complexo que não se restringe a uma única dimensão e não possui um único responsável, ocupando espaço de relevância no cenário das políticas públicas educacionais. Desse modo, a evasão, definida como a desistência do aluno do curso, é classificada como um dos maiores problemas de qualquer nível de ensino, tornando-se cada vez mais constante e de difícil mensuração por envolver dimensões histórica, cognitiva, social, afetiva e cultural (Jardim, 2015).

Diante disso, avaliar e controlar a evasão escolar são tarefas importantes tanto para o discente quanto para a instituição de ensino. Para o discente, por interferir na sua vida profissional, e para a instituição de ensino, por prejudicar o cálculo das taxas de rendimento escolar, pois esses índices têm como base o somatório do número de estudantes aprovados, reprovados e evadidos em um dado ano letivo. Tais taxas são usadas para o monitoramento da qualidade da instituição.

Dessa forma, este artigo tem como objetivo analisar a evasão escolar dos discentes considerados em situação de vulnerabilidade socioeconômica e suas relações com o Programa Nacional de Assistência Estudantil implementado pelo Instituto Federal de Ciência e Tecnologia do Norte de Minas - Campus Almenara no período de 2012 a 2016, a partir do uso da metodologia econométrica de Dados em Painel.

\section{Referencial Teórico}

\subsection{Políticas públicas da educação}

As políticas públicas são definidas como um conjunto de ações estratégicas que têm como objetivo promover o desenvolvimento de modelos econômicos e sociais nas diversas áreas, na qual as características são resultantes das forças endógenas da própria sociedade. Elas são compreendidas ainda como um fato baseado em aspectos históricos e sociais que demonstram os interesses de vários atores sociais e que refletem os valores presentes na sociedade (Souza, 2013).

Quando se trata de questões sociais, a Constituição Federal de 1988 traz em seu título VIII direitos relacionados à ordem social, e o capítulo III aborda especificamente os direitos voltados para a educação. No Art. 206 está previsto que o ensino será ministrado com base nos princípios da igualdade de condições para o acesso e permanência na escola; na liberdade de aprender, ensinar, pesquisar e divulgar o pensamento, a arte e o saber; no pluralismo de ideias e de concepções pedagógicas, e coexistência de instituições públicas e privadas de ensino; na gratuidade do ensino público em estabelecimentos oficiais; na valorização dos profissionais da educação escolar, garantidos, na forma da lei, planos de carreira, com ingresso exclusivamente por concurso público de provas e títulos, aos das redes públicas; na gestão democrática do ensino público, na forma da lei; na garantia de padrão de qualidade; e no piso salarial profissional nacional para os profissionais da educação escolar pública, nos termos de lei federal (Brasil, 1988).

Quando se trata das políticas públicas voltadas para educação, Colares (2005) relata que as ações para esta área fazem parte das chamadas políticas públicas sociais, que são elaboradas e implementadas pelos governos nacionais, com o intuito de diminuir as desigualdades de renda e oportunizar à parcela da sociedade que é classificada em situação de vulnerabilidade social e econômica. 
Salienta-se que ao propor a democratização da educação e o direito à educação de qualidade, o Estado deve garantir também a permanência do estudante no âmbito educacional. As políticas públicas educacionais apenas serão efetivas se, além de assegurar o acesso e a qualidade, promover ainda a permanência do educando.

Frente a isso, quando a economia mundial capitalista entrou em crise no pós-guerra, fazendo emergir altas taxas de inflação ajustada com baixas taxas de crescimento, mudanças significativas foram realizadas no cenário global. A partir daí as ideias neoliberais passaram a criticar o intervencionismo e pregar a atuação mínima do Estado nas políticas sociais (Andrade, 2011). Para retomar o crescimento econômico o Estado foi reestruturado por meio de reformas apoiadas no discurso de modernização e racionalização das práticas governamentais.

No Brasil, a administração pública também passou pela reestruturação, onde se criaram modelos e paradigmas (Rocha, 2001). Na década de 80, foi implantada a reforma gerencial do Estado, conhecida como reforma da gestão pública que se inspirava nas estratégias de gestão das empresas privadas, sendo nomeada de nova gestão pública (Bresser-Pereira, 2017).

No rol das relações sociais, o sistema educacional brasileiro também passou por reformas, e durante os dois mandatos do então presidente Fernando Henrique Cardoso (1995-2002) houve uma diminuição de investimentos públicos para esse setor e simultaneamente, incentivo empresarial aos níveis superiores de educação (Andrade, 2011).

Em 2007, no governo de Luiz Inácio Lula da Silva, o Estado retomou as bases da política intervencionista e implementou o Plano de Desenvolvimento da Educação - PDE, voltado para a educação superior. O projeto contemplava cerca de quatro dezenas de medidas, entre elas o Decreto №. 6.096 que institui o Programa de Apoio a Planos de Reestruturação e Expansão das Universidades Federais - REUNI. Este decreto tinha como foco as Instituições Federais de Ensino Superior, que historicamente não estavam incluídas na pauta de prioridades do governo.

O REUNI teve como principal objetivo ampliar o acesso e a permanência na educação superior, e para atingi-lo o governo federal adotou uma série de medidas para retomar o crescimento do ensino superior público, criando condições para que as universidades federais promovessem a expansão física, acadêmica e pedagógica da rede federal de educação superior.

Para garantir que o estudante que teve acesso ao ensino pela reestruturação das Instituições Federais de Ensino Superior tivesse sucesso na conclusão de seus estudos, o governo implantou, em 2010, o Plano Nacional de Assistência Estudantil (PNAES). O objetivo é viabilizar a igualdade de oportunidades entre todos os estudantes e contribuir para a melhoria do desempenho acadêmico, a partir de medidas que buscam combater situações de repetência e evasão (Brasil, 2017).

A seguir, estão listados alguns estudos recentes sobre o assunto com o intuito de conhecer a abordagem dos autores.

\subsection{Produção acadêmica sobre o Programa Nacional de Assistência Estudantil - PNAES}

O Programa Nacional de Assistência Estudantil - PNAES se apoia em princípios legais para realização de suas práticas. Tais princípios, além de estarem presentes na Constituição Federal de 1988, também se encontram na Lei de Diretrizes e Bases da Educação, aprovada em 20/12/1996, que contém dispositivos que amparam a assistência estudantil, entre os quais se destaca: "Art. 3ㅇ- O ensino deverá ser ministrado com base no seguinte princípio: I - igualdade de condições para o acesso e permanência na escola".

Com o intuito de tomar conhecimento sobre o que alguns pesquisadores estão abordando a respeito dos temas tratados neste estudo, foi realizada uma busca por produções acadêmicas concernentes ao Programa de Assistência Estudantil - PNAES, em artigos, dissertações e teses, delimitados entre os anos de 2012 e 2016, 
período que compreende a coleta de dados para avaliação da política por resultados do IFNMG Campus Almenara e estudos compreendidos nos anos de 2017 e 2018, anos de construção desta pesquisa.

A seleção ocorreu no portal de periódicos da Capes, Scielo e Repositórios Institucionais das universidades e Institutos Federais, utilizando os termos "Avaliação do Programa Nacional de Assistência Estudantil". A partir daí, selecionaram-se quatro dissertações e sete artigos para construção deste trabalho.

De acordo com Betzek (2015), o PNAES configura uma política de enfrentamento da evasão escolar e, num período de cinco anos, desde sua implementação, quase que quintuplicou os valores investidos. Betzek (2015, p. 81) destaca ainda que a assistência estudantil está prevista em leis e é estratégica para permitir que jovens, principalmente os que se encontram em situação de vulnerabilidade social, tenham a oportunidade de se ingressar em um curso superior.

Segundo Brito e Barbosa (2017, p. 134) "deve considerar a necessidade de viabilizar a igualdade de oportunidades, contribuir para a melhoria do desempenho acadêmico e agir, preventivamente, nas situações de retenção e evasão decorrentes da insuficiência de condições financeiras".

Para Carvalho (2013), ainda não existe um critério único adotado pelas Instituições Federais de Ensino brasileiras para avaliação socioeconômica de seus estudantes ou mesmo clareza sobre a definição dessa vulnerabilidade. 0 Ministério da Educação tem adotado o critério de renda per capita bruta igual ou inferior a 1,5 salário mínimo como critério de elegibilidade, a exemplo do Programa de Cotas (BRASIL, 2012) e do Programa de Bolsa Permanência (Brasil, 2013).

Destaca-se que "a categorização de vulnerabilidade socioeconômica para elegibilidade dos usuários às políticas de assistência estudantil é condição central para o acompanhamento dos resultados dessas políticas" (Carvalho, 2013, p.75).

Na visão de Terra (2015), os estudantes são previamente avaliados de acordo com sua situação de vulnerabilidade socioeconômica, segundo critérios adotados pelas Instituições Federais de Ensino Superior. De acordo com o autor, esses critérios são baseados no documento do FONAPRACE, elaborado em 1993.

O Quadro 1 sintetiza as publicações selecionadas para o presente estudo.

Quadro 1

Produção acadêmica sobre o PNAES - 2013 a 2018.

\begin{tabular}{|c|l|}
\hline $\begin{array}{c}\text { Tipo de trabalho/ano/ } \\
\text { autor }\end{array}$ & \multicolumn{1}{c|}{ Resultados da pesquisa } \\
\hline $\begin{array}{c}\text { Dissertação/2013 } \\
\text { (CARVALHO, 2013) }\end{array}$ & $\begin{array}{l}\text { A política de assistência estudantil tem alcançado os objetivos propostos. Entretanto, } \\
\text { verifica-se um alto índice de evasão nos cursos noturnos com significativa proporção de } \\
\text { estudantes em condição de vulnerabilidade socioeconômica. }\end{array}$ \\
\hline $\begin{array}{c}\text { Dissertação/2015 } \\
\text { (TERRA, 2015) }\end{array}$ & $\begin{array}{l}\text { A efetividade do PNAES se confirma com o atendimento aos estudantes menos favorecidos } \\
\text { financeiramente, minimizando os fatores que levam à evasão, assegurando as condições } \\
\text { básicas para que esses possam ter rendimento acadêmico satisfatório. }\end{array}$ \\
\hline $\begin{array}{c}\text { Dissertação/2015 } \\
\text { (QUEIROZ, 2015) }\end{array}$ & $\begin{array}{l}\text { Nem todos os alunos vulneráveis são contemplados pela Política de Assistência Estudantil, e } \\
\text { aqueles que são não têm suas } \\
\text { necessidades básicas satisfeitas na íntegra. Por conseguinte, os alunos buscam outras } \\
\text { estratégias para a garantia da permanência }\end{array}$ \\
\hline $\begin{array}{c}\text { Dissertação/2015 } \\
\text { (BETZEK, 2015) }\end{array}$ & $\begin{array}{l}\text { As medidas do PNAES colaboram com a democratização da permanência dos estudantes } \\
\text { em condições socioeconômicas desfavoráveis no ensino. }\end{array}$ \\
\hline Artigo/2015 & $\begin{array}{l}\text { Os dados referentes à criação dos institutos federais de educação e, particularmente, do } \\
\text { IFTO, comprovam a ampliação de vagas na educação profissional. Visando a atender a este } \\
\text { preceito, o exercício profissional na área educacional tem como ponto focal o }\end{array}$ \\
\hline
\end{tabular}




\begin{tabular}{|c|c|}
\hline $\begin{array}{c}\text { Tipo de trabalho/ano/ } \\
\text { autor }\end{array}$ & Resultados da pesquisa \\
\hline $\begin{array}{l}\text { (ROSA; AMORIM E } \\
\text { MACEDO, 2015) }\end{array}$ & $\begin{array}{l}\text { desenvolvimento e execução de programas e projetos que promovam o acesso, a } \\
\text { permanência e o melhor aproveitamento escolar dos estudantes, buscando alternativas } \\
\text { para os desafios impostos pela dinâmica da ordem do capital que interfere no acesso e } \\
\text { qualidade da política educacional. }\end{array}$ \\
\hline $\begin{array}{c}\text { Artigo/2016 } \\
\text { (VELOSO E SILVA, 2016) }\end{array}$ & $\begin{array}{l}\text { Os indicadores apontam que os referidos programas aumentaram as possibilidades de } \\
\text { acesso às instituições de ensino, refletindo em vagas e no ingresso, mas não repercutem na } \\
\text { permanência do estudante no curso. }\end{array}$ \\
\hline $\begin{array}{l}\text { Artigo/2017 } \\
\text { (BRITO E BARBOSA, } \\
\text { 2017) }\end{array}$ & $\begin{array}{l}\text { O estudo concluiu que o programa analisado contribui para minimizar as desigualdades } \\
\text { socioeconômicas, tendo em vista as iniciativas voltadas para a democratização do acesso e } \\
\text { a formação para a cidadania, bem como a permanência no curso. }\end{array}$ \\
\hline $\begin{array}{l}\text { Artigo/2017 } \\
\text { (ANDRADE E TEIXEIRA, } \\
\text { 2017) }\end{array}$ & $\begin{array}{l}\text { Resultados indicaram correlações baixas ou inexistentes das variáveis alvo com as áreas do } \\
\text { PNAES. Destacou-se o desenvolvimento psicossocial relacionado a todas as variáveis } \\
\text { analisadas. Implicações dos resultados para o aprimoramento das políticas e das ações de } \\
\text { apoio ao êxito acadêmico são discutidas. }\end{array}$ \\
\hline $\begin{array}{l}\text { Artigo/ } 2018 \\
\text { (RECKTENVALD; MATTEI } \\
\text { E PEREIRA, 2018) }\end{array}$ & $\begin{array}{l}\text { O estudo considera a necessidade da epistemologia dialética para o aperfeiçoamento do } \\
\text { PNAES, mesmo tendo constatado que, na atual conjuntura, há maior identificação com a } \\
\text { epistemologia da complexidade. }\end{array}$ \\
\hline
\end{tabular}

Fonte: Elaborada a partir das publicações dos portais periódicos da Capes, Scielo e Repositórios Institucionais das universidades e Institutos Federais, 2018

A presente pesquisa buscou realizar um levantamento de estudos sobre a evasão escolar no IFNMG, conforme se observa a seguir, como o intuito de compreender o que outros pesquisadores estão abordando atualmente sobre este tema.

\subsection{Produção acadêmica sobre evasão escolar no IFNMG}

As variáveis que influenciam a evasão escolar não estão ligadas apenas a condições financeiras, mas também a condicionantes relacionadas ao contexto social e cognitivo dos discentes. Esse fato leva a ponderar que essa política assistencial vai além de disponibilização de recursos, mas, se for aplicada de forma efetiva, pode alterar realidades locais.

Em sua pesquisa sobre evasão escolar Jardim (2015) cita que "o problema da falta de tempo do aluno, aliada à necessidade de mais atenção para a solução de dúvidas, por exemplo, se sobrepõem a um motivo clássico para a evasão, a falta de dinheiro para a continuidade do curso" (Jardim, 2015, p. 69).

Os estudos de Magalhães (2015), objetiva compreender, através de uma análise sociológica, os motivos pelos quais um grupo de entrevistados desistiu da escola. As conclusões apontadas pela maioria são [...] !a saída da escola se deu ainda na adolescência, para resolver, naquela ocasião, um problema imediato. A carência, a fome, ocasionada pela ausência de recursos financeiros e, portanto, a necessidade de trabalhar para ganhar algum dinheiro" (MAGALHÃES, 2015, p. 73).

Para Silva e Dore (2016), pode-se relacionar a evasão a aspectos individuais dos estudantes ou a aspectos da instituição. Conforme as autoras, os motivos individuais para a desistência escolar vão desde fatores econômicos e psicossociais, como a necessidade de trabalhar, até a falta de interesse pelo curso. Já os motivos ligados à instituição envolvem o projeto político pedagógico, a formação e atitudes dos professores, o atendimento educacional especializado, dentre outros.

Nas pesquisas de Fernandes e Bosco (2016), os fatores "relação com o trabalho", "mobilidade" e "dificuldade de transporte" aparecem como questões que mais motivaram a evasão escolar dos alunos.

O Quadro 2 apresenta uma caracterização dos trabalhos recentes selecionados sobre evasão escolar no IFNMG. 
Quadro 2

Produção acadêmica sobre evasão escolar no IFNMG - 2013 a 2018.

\begin{tabular}{|c|c|}
\hline $\begin{array}{c}\text { Tipo de trabalho/ } \\
\text { ano/autor }\end{array}$ & Resultados da pesquisa \\
\hline $\begin{array}{l}\text { Dissertação/2015 } \\
\text { (Sá Jardim, 2015) }\end{array}$ & $\begin{array}{l}\text { A pesquisa revelou que foram os aspectos exógenos os maiores causadores da evasão nos } \\
\text { cursos, com predominância da falta de tempo dos alunos para estudar, fazer as atividades e } \\
\text { participar do curso, a sobrecarga e acúmulo de atividades no trabalho, carga horária de } \\
\text { trabalho intensa, dificuldade em conciliar encontros presenciais com os sábados letivos do } \\
\text { calendário escolar e dificuldades em acompanhar o desenvolvimento do curso. }\end{array}$ \\
\hline $\begin{array}{l}\text { Dissertação/2015 } \\
\text { (Magalhães, 2015) }\end{array}$ & $\begin{array}{l}\text { Constatou-se que os alunos acessam o curso visando concluir o ensino médio e o avaliam } \\
\text { como oportunidade estratégica de crescimento pessoal e profissional. Além da propensão } \\
\text { familiar e dos condicionantes sociais, as narrativas incitaram reflexões em torno da } \\
\text { experiência profissional x inserção social e trabalho x diploma. } \\
\text { Questões de gênero, indicadores de subversão e as novas relações sociais construídas a partir } \\
\text { do ingresso no curso surgiram como intervenientes na construção do percurso escolar dos } \\
\text { alunos pesquisados. }\end{array}$ \\
\hline $\begin{array}{c}\text { Dissertação/2015 } \\
\text { (Batista, 2015) }\end{array}$ & $\begin{array}{l}\text { O cotidiano escolar é marcado pelo constrangimento e pela violência simbólica que se } \\
\text { evidenciam sobretudo através de imagens pejorativas e pela desvalorização do mundo rural } \\
\text { no espaço urbano. Estes elementos são significativos quando observamos o alto índice de } \\
\text { reprovação e abandono por parte do público que frequentam tais espaços. . }\end{array}$ \\
\hline $\begin{array}{l}\text { Artigo/2013 } \\
\text { (Alkimin, Amaral y } \\
\text { Leite, 2013) }\end{array}$ & $\begin{array}{l}\text { Os resultados revelam a necessidade de melhorias na Educação Básica com o objetivo de } \\
\text { contribuir para amenizar o alto índice de repetência, necessidade de investimento em } \\
\text { orientações vocacionais para alunos do Ensino Médio e ainda a necessidade de investimento } \\
\text { em políticas públicas voltadas para melhorias na carreira docente, que possam atrair os jovens } \\
\text { para o exercício desta profissão. }\end{array}$ \\
\hline $\begin{array}{l}\text { Artigo/2014 } \\
\text { (Almeida, Santos, } \\
\text { Almeida Júnior y } \\
\text { Almeida, 2014) }\end{array}$ & $\begin{array}{l}\text { A evasão escolar é considerada um fenômeno complexo e multicausal. Entender os fatores } \\
\text { que influenciam esse processo é importante para o aprimoramento das políticas públicas em } \\
\text { educação e para um melhor resultado no atendimento à população. }\end{array}$ \\
\hline $\begin{array}{c}\text { Artigo/2016 } \\
\text { (Silva y Dore, 2016) }\end{array}$ & $\begin{array}{l}\text { Os resultados mostram que os fatores associados ao abandono escolar de alunos com } \\
\text { deficiência apresentam aspectos similares aos dos alunos evadidos em geral. Abrangem, por } \\
\text { exemplo, a dificuldade de conciliar estudo e trabalho. Há, contudo, aspectos que dizem } \\
\text { respeito apenas aos alunos com deficiência, tais como a acessibilidade, a ausência do } \\
\text { atendimento educacional especializado, inclusive domiciliar e hospitalar. }\end{array}$ \\
\hline $\begin{array}{l}\text { ARTIGO/2016 } \\
\text { (Fernandes y Bosco, } \\
\text { 2016) }\end{array}$ & $\begin{array}{l}\text { Considerando que a evasão é a culminância de um processo multicausal, percebe-se que a } \\
\text { necessidade de trabalhar, na medida em que demanda tempo do aluno (tempo este que } \\
\text { poderia ser aproveitado em atividades escolares), associada à dificuldade em conciliar } \\
\text { trabalho e estudo (consequência também do menor tempo disponível), configuram-se em } \\
\text { fatores importantes na decisão pela evasão. }\end{array}$ \\
\hline
\end{tabular}

Fonte: Elaborada a partir das publicações dos portais periódicos da Capes, Scielo e Repositórios Institucionais das universidades e Institutos Federais, 2018.

\section{Metodologia}

Para coleta de dados foram selecionados os estudantes que ingressaram no IFNMG Campus Almenara por processo seletivo e vestibular e concorreram aos editais de assistência estudantil, sendo considerados em situação de vulnerabilidade e que se classificam nas seguintes categorias: oriundos da Rede Pública de Ensino, respeitando a proporção mínima de autodeclarados pretos, pardos e indígenas e as vagas reservadas para pessoas com deficiência ( $\mathrm{PCD}$ ). Esta seleção aconteceu pela análise do questionário socioeconômico, entre os anos de 2012 a 2016. Foram coletados os seguintes dados secundários: total de matriculados na instituição; total 
de matrículas por grupo de vulneráveis; beneficiários de programas sociais, local de moradia; renda per capita da familia; tipos de auxílio por curso (Tabela1).

Tabela 1

Variáveis do modelo

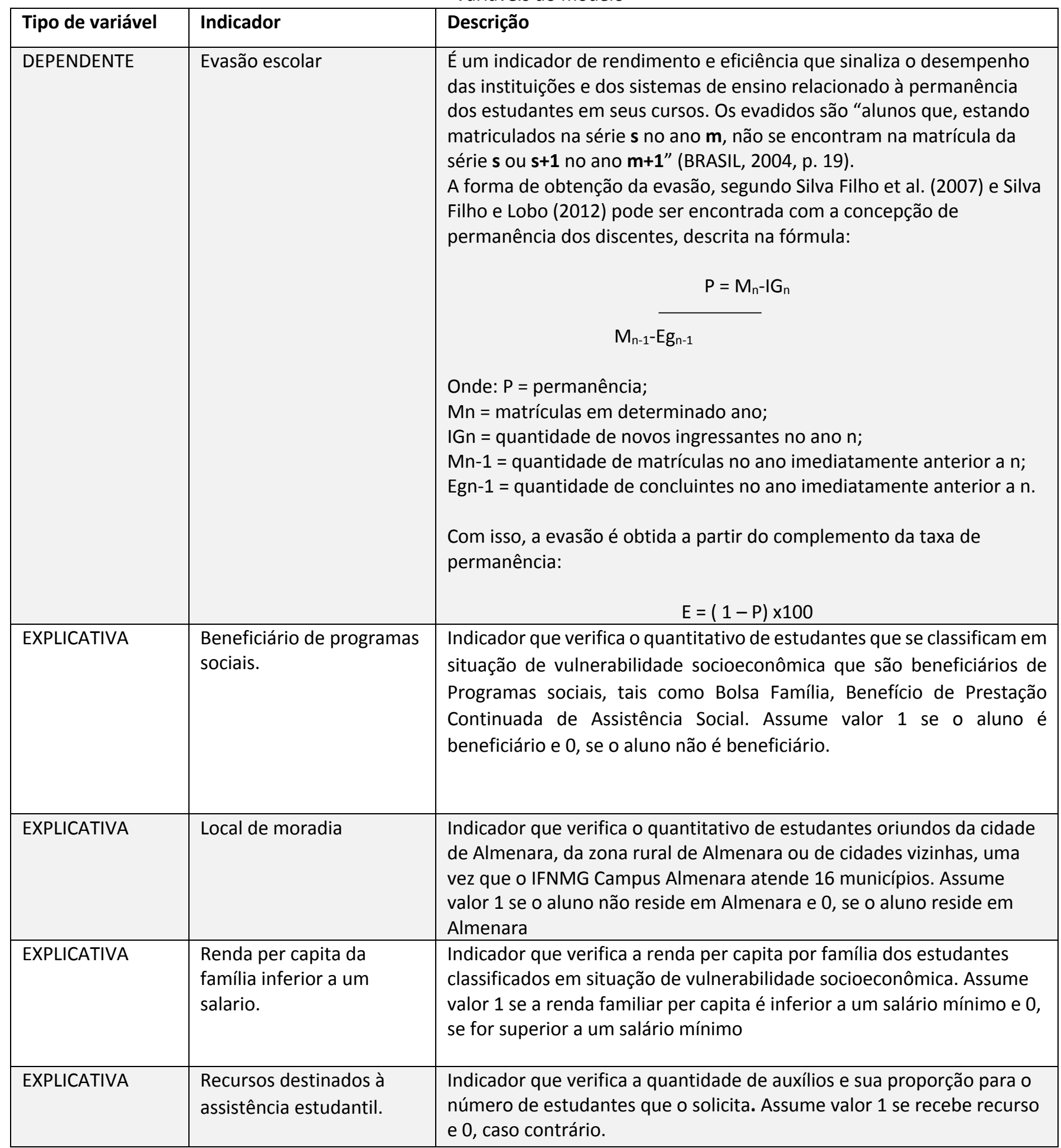

Fonte: Elaboração própria com base nos questionários socioeconômicos do IFNMG Campus Almenara

A escolha pelos dados secundários listados foi baseada no documento da FONAPRACE de 1993 que classifica os estudantes em situação de vulnerabilidade socioeconômica a partir dos critérios: composição familiar; renda dos familiares; situação de saúde dos membros da família; situação de escolaridade dos dependentes; grau de 
instrução e ocupação dos pais; bens patrimoniais da família; curso do aluno; moradia do aluno; e meios de transporte dos alunos para fins de avaliação dos candidatos aos benefícios do Programa Nacional de Assistência Estudantil - PNAES. Além disso, tais critérios também são utilizados pelo IFNMG Campus Almenara para selecionar seus estudantes beneficiários.

O levantamento de dados foi realizado através da pesquisa documental, utilizando-se de consultas aos Relatórios de Gestão do Exercício do IFNMG de 2012 a 2016, Plano Estratégico Institucional de Permanência e Êxito dos Estudantes do IFNMG, Resultados da Assistência Estudantil do IFNMG Campus Almenara sobre vulnerabilidade socioeconômica, Relatórios da Secretaria do Campus Almenara e Relatórios do Departamento de Administração e Planejamento - DAP do Campus Almenara.

Com o objetivo de analisar a relação entre a evasão escolar e o Programa de Assistência Estudantil - PNAES no Campus Almenara, foi utilizado neste trabalho o modelo de dados em painel, para o qual características dos alunos da unidade Campus Almenara são acompanhadas ao longo do tempo, de modo a verificar sua relação com a evasão escolar.

O modelo de dados em painel é assim descrito:

$$
Y_{i}=\beta_{0}+\beta_{1 \times i}+\varepsilon_{i}
$$

Em que:

Yi: Valor observado para a variável dependente Y no i-ésimo nível da variável independente X;

$\beta_{0}$ : Constante de regressão - Representa o intercepto da reta com o eixo dos Y;

$\beta_{1}$ : Coeficiente de regressão - Representa a variação de Y em função da variação de uma unidade da variável X;

xi: I-ésimo nível da variável independente $X(i=1,2, \ldots, n)$;

$\varepsilon_{\mathrm{i}}$ : É o erro que está associado à distância entre o valor observado Yi e o correspondente ponto na curva, do modelo proposto, para o mesmo nível i de $\mathrm{X}$.

Foram apresentadas as estimações por Mínimos Quadrados Ordinários (MQO), que consiste em adotar os estimadores que minimizam a soma dos quadrados dos desvios entre valores estimados e valores observados na amostra (HOFFMANN, 2016). Assim, tem-se que:

$$
\varepsilon_{i}=Y_{i}-\beta_{0}-\beta_{1 \times i}
$$

Elevando ambos os membros ao quadrado,

$$
\varepsilon_{i}^{2}=\left[Y_{i}-\beta_{0}-\beta_{1 x i}\right]^{2}
$$

Aplicando o somatório,

$$
\sum_{i-1}^{n} \varepsilon_{i}^{2}=\sum_{i-1}^{n}\left[Y_{i}-\beta_{0}-\beta_{1 \times i}\right]^{2}
$$

Por meio da obtenção de estimadores de $\beta_{0}$ e $\beta_{1}$, que minimizem o valor obtido na expressão anterior, é possível alcançar a minimização da soma de quadrados dos erros. Derivando então a expressão anterior em relação a $\beta_{0}$ e $\beta_{1}$, temos:

$$
\beta_{0}=Y-\beta_{1} X
$$


Uma vez obtidas estas estimativas, podemos escrever a equação estimada:

$$
Y_{i}=\beta_{0}+\beta_{1} X_{i}
$$

Segundo Montenegro, Diniz e Simões (2016, p.9) "no modelo de dados em painel pode ocorrer problemas relacionados ao enviesamento de seleção, isto é, erros resultantes da seleção dos dados que não formem uma amostra aleatória. Dessa forma, questões como a auto seletividade (amostras truncadas) e ausência de resposta ou atrito podem ser consideradas, o que podem ser considerados de efeitos não observados".

Para a modelagem dos efeitos não observados existem duas possibilidades: os efeitos fixos e os efeitos aleatórios. $O$ termo efeitos fixos "deve-se ao fato de que, embora o intercepto (o ponto em que a reta regressora corta o eixo dos $\mathrm{y}$, quando $\mathrm{x}=0$ ) possa diferir entre os indivíduos, o intercepto de cada indivíduo não varia com o tempo; ele é invariante no tempo" (GUJARATI; PORTER, 2011, p.592). Quanto ao modelo de efeitos aleatórios, pressupõe-se que o intercepto (aleatório) de uma unidade individual não estão correlacionados com as variáveis explicativas (GUJARATI E PORTER, 2011).

Ao se realizar a modelagem nos dados em painel e comparar os resultados do efeito fixo e as regressões de efeito aleatório, perceberá que há diferenças substanciais entre os dois. A escolha do melhor modelo foi realizada via Teste de Hausman, cuja hipótese nula subjacente é a de que os estimadores do modelo de efeito fixo e do modelo de componentes não diferem substancialmente. O teste estatístico desenvolvido por Hausman tem uma distribuição assintótica. Se a hipótese nula for rejeitada, a conclusão é que o MCE não é adequado, porque os efeitos aleatórios provavelmente estão correlacionados com um ou mais regressores. Nesse caso, o modelo de efeitos fixos é preferível aos de efeitos aleatórios (Gujarati y Porter, 2011).

\section{Resultados}

\subsection{Análise descritiva}

Do total de alunos matriculados, foram colhidas informações do número de discentes em situação de vulnerabilidade socioeconômica (público-alvo do PNAES) e realizada uma comparação entre o quantitativo de auxílios ofertados e o quantitativo de alunos beneficiados. Posteriormente, foram apresentadas informações sobre o quantitativo de evadidos. Feito isso, estabeleceu-se uma relação entre o público-alvo do PNAES e o os alunos atendidos(Tabela 2).

Tabela 2

Alunos contemplados pela

Assistência Estudantil

\begin{tabular}{lcccccc}
\hline ANO & $\begin{array}{c}\text { Total de alunos } \\
\text { presenciais } \\
\text { matriculados }\end{array}$ & $\begin{array}{c}\text { Público com } \\
\text { vulnerabilidade } \\
\text { social (no) }\end{array}$ & $\begin{array}{c}\text { \% vulnerabilidade } \\
\text { social }\end{array}$ & $\begin{array}{c}\text { Auxílios } \\
\text { ofertados }\end{array}$ & $\begin{array}{c}\text { Alunos } \\
\text { com } \\
\text { benefícios }\end{array}$ & $\begin{array}{c}\text { \% } \\
\text { De alunos } \\
\text { com } \\
\text { benefícios }\end{array}$ \\
\hline $\mathbf{2 0 1 2}$ & 963 & 818 & 84,98 & 80 & 74 & 9,04 \\
$\mathbf{2 0 1 3}$ & 1775 & 1328 & 74,86 & 658 & 328 & 24,69 \\
$\mathbf{2 0 1 4}$ & 739 & 515 & 69,75 & 354 & 354 & 36,76 \\
$\mathbf{2 0 1 5}$ & 1034 & 719 & 69,61 & 354 & 349 & 48,53 \\
$\mathbf{2 0 1 6}$ & 1067 & 963 & 90,27 & 381 & 341 & 35,41 \\
\hline
\end{tabular}

Fonte: Elaborada com base nos Relatórios de Gestão do IFNMG. Acesso em 2018 
O IFNMG Campus Almenara recebeu suas primeiras matrículas no ano de 2010, após implantação do campus no Baixo Vale do Jequitinhonha; foi no ano de 2011 que se registrou um número significativo de alunos devido à expansão de vagas na instituição. Em 2011, foram efetuadas 609 matrículas.

Consta no Relatório de Gestão (2012, p. 149) que a "maior parte dos alunos pesquisados que ingressaram no campus era de baixa renda (aproximadamente $70 \%$ apresentava uma renda per capta inferior a um salário mínimo)". Tal informação pode ser explicada pelo contexto em que o campus está inserido, uma vez que os 16 municípios que pertencem à microrregião de Almenara, estão abaixo do IDHM nacional. Além disso, foi apontado ainda que $56 \%$ dos municípios situavam na faixa do desenvolvimento médio (IDHM entre 0,600 e 0,699) no ano de 2010, e 44\% dos municípios encontravam-se em situação crítica por terem um índice de baixo desenvolvimento humano.

No ano de 2012 houve a regulamentação da Política de Assistência Estudantil do IFNMG, e o Campus Almenara contou com um crescimento no número de matrículas. Do total de matriculados (963), 84,98\% se encontrava em situação de vulnerabilidade socioeconômica, mas o número de auxílios ofertados foi muito baixo para atender à demanda, como se pode observar na Tabela 1 . Além de serem ofertados poucos auxílios (80), apenas 74 foram repassados.

Nos anos de 2013, 2015 e 2016 também houve uma evolução no número de matrículas realizadas, mas os auxílios ofertados continuaram aquém do aguardado.

O Gráfico 1 apresenta a relação entre o público-alvo do PNAES e o público-alvo atendido pelo IFNMG Campus Almenara.

\section{Gráfico 1}

Relação entre o público-alvo do PNAES e o

público-alvo atendido pelo IFNMG Almenara

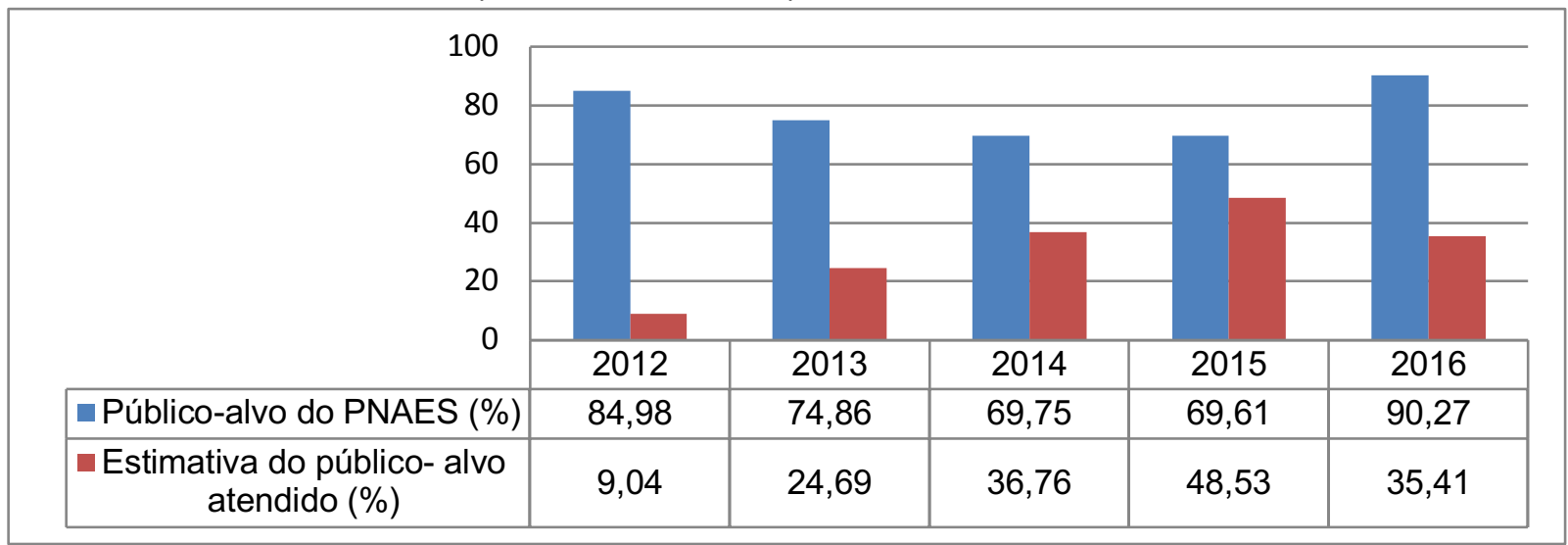

Fonte: Elaborada com base nos Relatórios de Gestão do IFNMG. Acesso em 2018

Ao analisar o Gráfico 1, nota-se que pelos critérios de avaliação de políticas públicas apresentados por Costa e Castanhar (2003), durante os anos de 2012 a 2016, o programa não atingiu os seus objetivos e metas, pois não conseguiu distribuir todos os benefícios ofertados. Além disso, o quantitativo de discentes em situação de vulnerabilidade socioeconômica foi alto e as estimativas de atendimento destes discentes foram muito baixas. Neste último caso, o governo federal não concedeu repasse suficiente de recursos para atender às propostas do programa.

Ao observar o impacto (ou efetividade), o projeto está conseguindo efeitos positivos no ambiente externo em que está interferindo, em termos técnicos, econômicos, socioculturais, institucionais e ambientais. Tal fato pode ser percebido, por exemplo, no aumento das matrículas ao longo dos anos avaliados.

A seguir analisam-se as influências externas da evasão escolar no IFNMG Campus Almenara e o que se percebe é que, mesmo que a renda seja um fator importante a ser considerado, não é a única que garante a permanência. 
Na relação entre o número de matriculados e o número de evadidos, podem-se perceber valores significativos, conforme demonstra o Gráfico 2 a seguir:

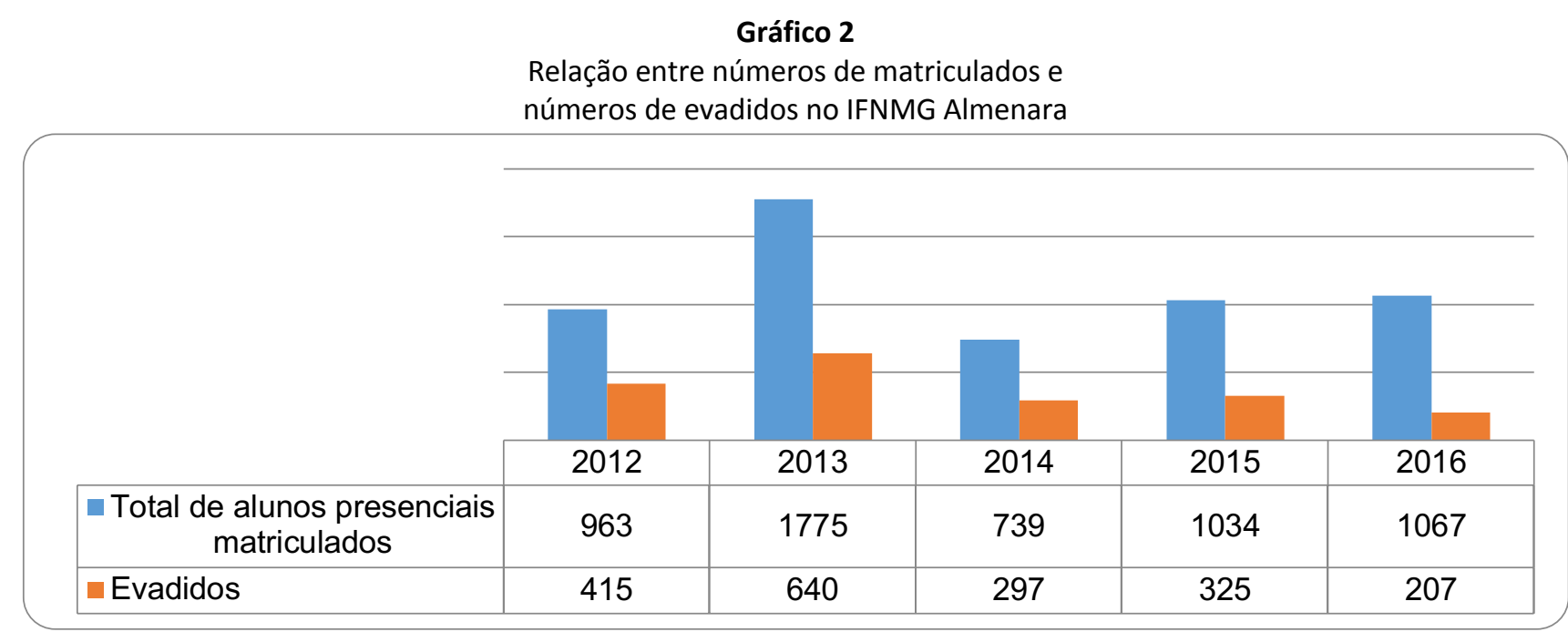

Fonte: Elaborado com base no Plano de Permanência e êxito do IFNMG. Acesso em 2018

O Gráfico 2 mostra que no ano de 2012 houve 43,19\% de evasão escolar em relação ao número total de matriculados. E nos anos de 2013, embora a evasão apresentasse um decréscimo, o índice ainda foi considerado alto, sendo 36,11\% de desistentes. Em 2014 a evasão voltou a aumentar, deixando a instituição em alerta com seu índice de $40,31 \%$ de alunos que decidiram sair.

Dentre as causas apontadas para a evasão, encontrava-se a dificuldade de adaptação à vida escolar do campus; dificuldade de aprendizagem e habilidade de estudo, bem como de planejamento dos estudos e deficiência nos conhecimentos prévios ao Ensino Médio por parte dos alunos; dificuldades financeiras do estudante/família (estudantes de baixa renda); baixa autoestima, transtornos psicológicos e emocionais, falta de planejamento, distração dos estudantes; falta de conhecimento e desmotivação com o curso e com as disciplinas técnicas; dificuldade na realização/complementação do estágio; falta de participação dos pais na escola; problemas financeiros, valores do transporte e permanência na cidade muito elevados; vulnerabilidade social dos estudantes da área rural; necessidade de cuidar dos filhos no horário do curso e dificuldade de conciliar estudo e trabalho (IFNMG, 2018).

Existe uma diversidade de situações que são associadas ao processo da evasão, que podem envolver os diferentes sujeitos, o sistema de avaliação, a reprovação, a retenção, os grupos de amigos, as práticas pedagógicas e escolares, relações com a família, com a comunidade, além dos diferentes níveis de engajamento com a vida e a prática escolar (IFNMG, 2018).

Verifica-se que o fator renda e renda per capita familiar ainda são os destaques para evitar a desistência do aluno de seus cursos, mas os motivos individuais vão desde fatores econômicos e psicossociais, como a necessidade de trabalhar, até a falta de interesse pelo curso.

Quanto àqueles classificados em situação de vulnerabilidade social, verificou-se que, em 2011, 64\% dos alunos viviam com renda per capita menor que 0,5 (meio) salário mínimo ou até 1 (um) salário mínimo. Em 2012 e 2013, essa quantidade continuou crescendo, passando de $66 \%$ a $84 \%$ respectivamente. Em 2014, embora o número de pesquisados com renda familiar per capita menor do que 1 salário mínimo tenha reduzido, esse indicador continuou alto, próximo a 78\%. A mesma linha foi seguida em 2015. Embora tenha caído o percentual, ainda sim era representado pela maioria dos alunos pesquisados, ou seja, 67,13\% (IFNMG, 2015). 
Estes alunos com renda familiar per capita de até 0,5 (meio) salário mínimo ou de até 1 (um) salário mínimo se enquadram no grupo de vulnerabilidade socioeconômica e estão mais propensos à evasão. Posto isso, o Gráfico 3 aponta o quantitativo de evadidos em situação de vulnerabilidade no Campus Almenara.

Gráfico 3

Evadidos em situação de vulnerabilidade

socioeconômica no IFNMG Campus Almenara

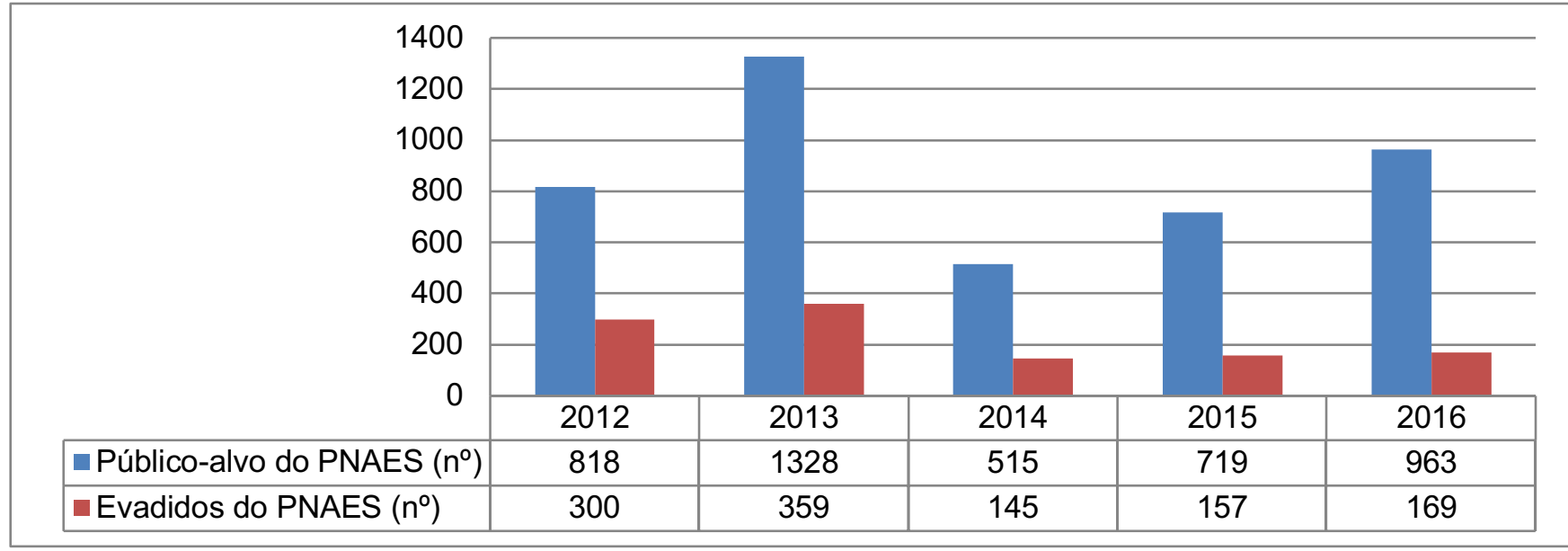

Fonte: Elaboração própria com base no Plano de Permanência e êxito do IFNMG

Observa-se no Gráfico 3 que, em 2012, 36,68\% (300) dos estudantes considerados em situação de vulnerabilidade socioeconômica desistiram de seus cursos. Entretanto, esses índices caíram ao longo dos anos, passando a 27,01\% em 2013; 28,88\% em 2014; 21,88\% em 2015, e 17,53\% em 2016.

Ao comparar o total de evadidos geral com o total de evadidos em situação de vulnerabilidade, constata-se que entre os discentes que fazem parte do público-alvo do PNAES houve menos evasão que o total geral. Isso ocorreu, principalmente, por causa dos benefícios concedidos.

Após as análises, deve-se considerar a importância do programa da assistência estudantil para a região do Baixo Vale do Jequitinhonha e para aqueles que dele conseguem se beneficiar, visto que diante de fatores históricos que influenciaram nos baixos índices de desenvolvimento humano e baixos índices de renda per capita familiar, os auxílios concedidos, embora que ainda poucos, estão permitindo o acesso e a permanência de uma parcela de discentes contemplados no ensino.

A base de dados secundários colhidos através dos questionários socioeconômicos foram confrontados em uma análise econométrica pelo modelo de regressão. Tais indicadores são utilizados não apenas para selecionar os discentes que serão contemplados pelo PNAES, mas também para definir qual tipo de auxílio cada discente receberá. Os resultados foram organizados na seção a seguir.

\subsection{Análise econométrica: modelo de dados em painel}

O modelo de dados em painel gerado, com o intuito de verificar a relação existente entre a evasão escolar no IFNMG Campus Almenara e as características essenciais para ser contemplado pelos programas de assistência estudantil ao longo do período compreendido entre 2012 e 2016, contou com 4982 observações.

O Quadro 3 a seguir retrata a correlação entre os indicadores analisados, com o intuito de se apurar o grau de relacionamento entre eles: 
Quadro 3

Correlação entre indicadores

\begin{tabular}{|l|l|l|l|l|l|}
\hline & $\begin{array}{l}\text { Evasão } \\
\text { escolar }\end{array}$ & $\begin{array}{l}\text { Beneficiário de } \\
\text { programas } \\
\text { sociais }\end{array}$ & $\begin{array}{l}\text { Local de } \\
\text { moradia }\end{array}$ & $\begin{array}{l}\text { Renda familiar } \\
\text { per capita < } \\
\text { um salário }\end{array}$ & $\begin{array}{l}\text { Renda } \\
\text { familiar } \\
\text { capita } \begin{array}{c}\text { mer } \\
\text { salário }\end{array}\end{array}$ \\
\hline Evasão escolar programas & 0.7941 & 1.0000 & & & \\
\hline $\begin{array}{l}\text { Beneficiário de } \\
\text { sociais }\end{array}$ & 0.7534 & 0.8001 & 1.0000 & & \\
\hline $\begin{array}{l}\text { Local de moradia } \\
\text { Renda familiar per capita um }\end{array}$ & 0.7760 & 0.7382 & 0.6538 & 1.0000 & \\
\hline $\begin{array}{l}\text { Recursos destinados à } \\
\text { assistência estudantil }\end{array}$ & 0.6487 & 0.7351 & 0.6814 & 0.8126 & 1.0000 \\
\hline
\end{tabular}

Fonte: Elaboração própria com base nos questionários socioeconômicos do IFNMG Almenara

Pode-se constatar que todos os indicadores apresentam correlação com a evasão escolar, sendo os mais relacionados os indicadores "beneficiários de programas sociais", alunos com renda familiar per capita inferior a um salário mínimo e local de moradia diferente daquele onde se situa o campus.

A estimação por Mínimos Quadrados Ordinários resultou nas informações contidas no Quadro 4 a seguir:

Quadro 4

Estimação por Mínimos

Quadrados Ordinários

\begin{tabular}{|l|c|c|c|}
\hline Evasão escolar & Coeficiente & Desvio-padrão & Significância ( $\mathrm{P}>|\mathrm{t}|)$ \\
\hline Beneficiários de programas sociais & .3350341 & .013359 & 0.000 \\
\hline Local de moradia & .2862476 & .0118544 & 0.000 \\
\hline Renda per capita da família inferior a um salário & .5255351 & .0136849 & 0.000 \\
mínimo & & & 0.000 \\
\hline Recursos destinados à assistência estudantil & -.2203975. & .0136172 & 0.003 \\
\hline Constante & -.0147666 & .0050109 & 0.003 \\
\hline
\end{tabular}

Fonte: Elaboração própria com base no Plano de Permanência e êxito do IFNMG

Conforme os resultados retratados todas as variáveis utilizadas no modelo são significativas para a explicação da evasão escolar no IFNMG - Campus Almenara. Os resultados dos coeficientes dos indicadores beneficiários de programas sociais, local de moradia e renda per capita da família são positivos, indicando que a correlação entre o indicador específico e a variável dependente (evasão escolar) são diretamente relacionados, de modo que o fato de ser beneficiário de programa social, de morar em local distante do campus e de pertencer a família com menor renda per capita aumenta a chance de evasão. Já os recursos destinados à assistência estudantil se relacionam negativamente com a evasão escolar, de modo que quantos maiores estes recursos, menores as chances de evasão. O modelo consegue explicar $74.4 \%$ dos valores observados para a evasão no IFNMG Campus Almenara (R2=0.7470).

O Quadro 5 retrata o resultado do modelo de dados em painel com efeitos fixos: 


\section{Quadro 5}

Resultado do modelo de dados em painel com efeitos fixos.

\begin{tabular}{|c|c|c|c|}
\hline Evasão escolar & Coeficiente & Desvio-padrão & Significância ( $\mathrm{P}>|\mathrm{t}|)$ \\
\hline Beneficiários de programas sociais & .3398178 & .0141247 & 0.000 \\
\hline Local de moradia & .2809702 & .0134822 & 0.000 \\
\hline Renda per capita da família & .4003314 & .0145386 & 0.000 \\
\hline Recursos destinados à assistência estudantil & -.4355796 & .0151072 & 0.000 \\
\hline Constante & .0965918 & .0082626 & 0.000 \\
\hline
\end{tabular}

Fonte: Elaboração própria com base nos questionários socioeconômicos do IFNMG Almenara

Para a modelagem dos efeitos não observados nos dados em painel, existem duas possibilidades: os efeitos fixos (Quadro 5) e os efeitos aleatórios (Quadro 6).

\section{Quadro 6}

Resultado do modelo de dados em painel com efeitos aleatórios

\begin{tabular}{|l|c|c|c|}
\hline Evasão escolar & Coeficiente & Desvio-padrão & Significância ( P>|t|) \\
\hline Beneficiários de programas sociais & .3350341 & .013359 & 0.000 \\
\hline Local de moradia & .2862476 & .0118544 & 0.000 \\
\hline Renda per capita da família & .5255351 & .0136849 & 0.000 \\
\hline Recursos destinados à assistência estudantil & -.2203975 & .0136172 & 0.000 \\
\hline Constante & -.0147666 & .0050109 & 0.003 \\
\hline
\end{tabular}

Fonte: Elaboração própria com base nos questionários socioeconômicos do IFNMG Almenara

No modelo de efeitos fixos considera-se que o intercepto específico de cada indivíduo pode estar correlacionado com um ou mais regressores. Quanto ao modelo de efeitos aleatórios, pressupõe-se que o intercepto (aleatório) de uma unidade individual não está correlacionado com as variáveis explicativas.

Ao analisar o teste de significância global para todos os modelos de todas as regiões, percebe-se que todos os modelos calculados foram significativos para prever a variável evasão escolar, através das variáveis utilizadas, uma vez que o 'Prob>F' ou 'Prob>chi2' foram menores que 0,05. Logo, em todos os casos, há evidências de que pelo menos uma variável explicativa esteja relacionada à variável dependente evasão escolar. Tanto para o modelo de efeitos fixos quanto para o modelo de efeitos variáveis, todas as variáveis utilizadas foram significativas para a explicação da evasão escolar. Em ambos os modelos, os recursos destinados à assistência estudantil se relacionam de forma negativa com a evasão escolar, indicando que um aumento na primeira ocasiona uma redução na segunda.

Ao se realizar o teste de Hausman, o Prob>chi2 $=0.0000$, o que indica que o modelo de efeitos fixos melhor representa os dados observados. Desse modo, pode-se inferir que ser aluno beneficiário de programas sociais aumenta a chance de evasão escolar em cerca de $34 \%$, o que possivelmente se relaciona à sua já presente condição de vulnerabilidade socioeconômica. Morar em local distante do campus (fora do município de Almenara) aumenta essa chance em $28 \%$, o que por sua vez retrata a dificuldade de alunos que, além de possuir uma condição socioeconômica vulnerável, possuem dificuldades no transporte para o campus, seja em razão da distância e/ou da própria condição econômica. Possuir renda per capita inferior a um salário mínimo aumenta a chance de evasão em $40 \%$, e ser beneficiário de programas de assistência estudantil reduz a evasão escolar em 22\%. Desse último resultado depreende-se a importância do programa de assistência estudantil do IFNMGCampus Almenara no sentido de reduzir as disparidades de permanência do aluno na instituição. 
Face aos resultados encontrados na análise econométrica, através do painel de dados, pode-se perceber que a evasão escolar no campus não está condicionada apenas a fatores internos, mas é determinada também por fatores externos. Ao discutir a política pública educacional no IFNMG Campus Almenara, destaca-se a fala de Jannuzzi (2005) sobre a importância da escolha de indicadores para diagnóstico, monitoramento e avaliação de programas sociais no Brasil. Esses indicadores permitem a operacionalização de demandas de interesses públicos.

O Campus Almenara utiliza as variáveis: renda per capita, local de moradia (se o discente reside em Almenara ou não) e se a família do aluno é beneficiária de programas sociais, para selecionar e contemplar os beneficiários do programa de assistência estudantil. Essas variáveis foram escolhidas dentre a lista de indicadores estabelecida pelo PNAES, no ano de 2007, organizadas após as pesquisas do perfil socioeconômico e cultural dos estudantes de graduação das IFES, realizadas pelo FONAPRACE entre 1996 e 1997 e entre 2003 e 2004.

A lista de indicadores do PNAES é padrão para todo o país; entretanto, observa-se que ela merece um aperfeiçoamento regional e uma atualização, respeitando as especificidades do contexto em que será aplicada. No aspecto uso de indicadores sociais para pontuar a oferta dos serviços em relação ao atendimento à demanda, o campus tem se preocupado em atender aos critérios de avaliação estabelecidos pela política pública educacional. Isso indica um impacto favorável na redução da evasão escolar nos anos considerados, como mostra o modelo.

\section{Conclusões}

O presente trabalho teve como objetivo analisar o programa de assistência estudantil implementado pelo Instituto Federal de Ciência e Tecnologia do Norte de Minas - Campus Almenara, em termos dos quesitos utilizados para eleição de seu público-alvo, assim como de seu impacto sobre a redução da evasão escolar no período de 2012 a 2016.

Sobre IFNMG, Campus Almenara, deve-se observar que está localizado em uma região de grande vulnerabilidade econômica e social, qual seja, o Vale do Jequitinhonha, no nordeste de Minas Gerais, de modo que a maior parte de seus discentes possuem baixa renda e são elegíveis ao programa estudantil. Para a seleção, foi considerada renda familiar per capita de até $1 \frac{1}{2}$ (um salário mínimo e meio).

Pôde ser percebido que a instituição enfrenta dificuldades para o desempenho orçamentário, ou por ineficiência no repasse financeiro do governo federal, ou por falta de informatização ou ainda por escassez de servidores. Em alguns anos, mesmo com o orçamento aprovado, não houve repasse de todo recurso.

Desse modo, considerando as áreas básicas definidas pelo próprio PNAES na garantia das condições de permanência dos discentes (alimentação, moradia, transporte, atenção à saúde, apoio pedagógico, entre outras), os valores por matrícula anualmente não foram suficientes para atender todo o público alvo considerado em situação de vulnerabilidade socioeconômica. Desse modo, a demanda foi bem maior que a oferta, deixando muitos estudantes fora da contemplação dos recursos.

Considerando não ser a renda o único fator que influencia a permanência do aluno no IFNMG, foram também analisadas as informações concernentes ao recebimento de outros auxílios sociais e local de moradia do discente. Pôde ser percebido que o fato de a família do discente receber outros auxílios possui relação positiva com a evasão, o que reitera a relação entre evasão e vulnerabilidade sócio-econômica. Também foi percebido que quanto maior a distância do local de moradia do aluno em relação ao campus, maior a evasão.

Em termos do impacto do programa sobre a evasão escolar, estimou-se que, para o período em análise, este foi de $22 \%$. Esse impacto, embora considerável, poderia ser mais significativo, caso o quantitativo de recursos 
oferecidos pelo programa, sempre aquém das necessidades do campus, fosse maior. Cabe, nesse interim, destacar a importância de se ampliar esse auxilio em prol de viabilizar a igualdade de oportunidades dos estudantes, garantindo o acesso e permanência dos alunos nos cursos do IFNMG. Ademais, reitera-se o potencial de impacto dessa política no que tange ao desenvolvimento dessa região, que de forma peculiar, se caracteriza pela pobreza e desigualdade.

Conclui-se que a política pública educacional de assistência estudantil, implementada no IFNMG Campus Almenara ainda precisa ser melhorada. A criação de dispositivos internos de avaliação poderiam contribuir com essas melhorias. Espera-se que esta pesquisa sirva como uma primeira avaliação e funcione como suporte para a identificação dos aspectos que necessitam de mudança, saindo da situação atual vivida (status quo) para uma situação ideal possível à realidade coletiva.

Outros fatores a serem considerados em trabalhos futuros são: conciliar trabalho e estudo, adaptação a um novo sistema de ensino, o que exige maior autonomia, conhecimentos prévios formais e informais de maior complexidade, e aprendizados nem sempre vivenciados pelos alunos de camadas mais populares também aumentam as probabilidades de evasão. Sugere-se, ademais, para estudos futuros que sejam feitas pesquisas qualitativas sobre a evasão escolar e os programas de assistência estudantil, buscando a percepção dos discentes, dos servidores responsáveis pelo núcleo e dos gestores do campus.

\section{Referências bibliográficas}

Almeida, M. F. F. et al(2014). Estudo comparativo das proporções de evasão nos cursos técnicos na modalidade subsequente e concomitante do IFNMG - Campus Montes Claros, sob uma visão estatística. Revista da Estatística da UFOP, v. 3. Disponível em: <http://www.cead.ufop.br/jornal/index. php/rest/article/view/607>. Acesso em: 15 ago. 2018.

Alkimin, M. E. F.; Amaral, T. R. do y Leite, N.(2018) Abandono escolar no curso de Licenciatura em Matemática do IFNMG - Campus Januária. Disponível em: <http://www.conferencias.ulbra.br/index. php/ciem/vi/paper/viewFile/1312/312>. Acesso em: 15 ago. 2018.

Andrade, D. C. T. et al (2011). A gestão pública e o REUNI: entre o social e o gerencial. Revista da Universidade Vale do Rio Verde, Três Corações, v. 9, p. 154-170, ago./dez. 2011. Disponível em: <http://dx.doi.org/10. 5892/ruvrv. 2011.92.154170>. Acesso em: 13 dez. 2017.

Andrade, A. M. J. de y TEIXEIRA, M. A. P. (2017). Áreas da política de assistência estudantil: relação com desempenho acadêmico, permanência e desenvolvimento psicossocial de universitários. Revista Avaliação, Campinas; v. 22, n. 2, p. 512-528, jul. 2017. Disponível em: <http://www.scielo.br/scielo. php?pid=S1414-772017000200512\&script=sci_abstract\&tlng=pt>. Acesso em: 15 ago. 2018.

Batista, E.C. C. (2015). Trajetórias Escolares de Jovens Assentados: Estudo em Arinos/MG. 2015. 157 p. Dissertação (Mestrado) - Universidade Federal de Santa Catarina, Centro de Ciências Humanas, Programa de Pós-Graduação em Sociologia Política, Florianópolis-SC.

Brasil(1988). Constituição Federal de 1988. Brasília, DF: Senado Federal: Centro Gráfico, 1988. 292 p.

Brasil (2012). Lei no 12.711, de 29 de agosto de 2012. Dispõe sobre o ingresso nas universidades federais e nas instituições federais de ensino técnico de nível médio e dá outras providências. Disponível em: http://www.planalto.gov.br/ccivil_03/_ato2011-2014/2012/lei/l12711.htm. Acesso em: 01/12/2017.

Brasil (2013). Programa de Bolsa Permanência. O Manual de Gestão do Programa de Bolsa Permanência (PBP). Disponível em: <http://permanencia.mec.gov.br/docs/manual.pdf>. Acesso em: 12 Nov. 2018. 
Brasil(2017). Acesso à informação - orçamento da assistência estudantil - PNAES. 2017b. Disponível em: <http://www.consultaesic.cgu.gov.br/busca/dados/Lists/Pedido/Item/displayifs.aspx?List=0c839f31-47d74485-ab65-ab0cee9cf8fe\&ID=570924\&Web=88cc5f44-8cfe-4964-8ff4-376b5ebb3bef>. Acesso em: 02 Nov. 2018.

Betzek, S. B. F. (2015). Avaliação do Programa Nacional de Assistência Estudantil - PNAES na UTFPR Campus Medianeira. 2015.139 f. Dissertação (Mestrado em Educação) Universidade Estadual Paulista, Faculdade de Filosofia e Ciências, Marília.

Bresser-Pereira, L. C. (2017). Reforma gerencial e legitimação do estado social. Revista de Administração Pública, Rio de Janeiro, v. 51, n. 1, p.147-156.

Bresser-Pereira, L. C. (2002). Reforma da nova gestão pública: agora na agenda da América Latina. Revista do Serviço Público, Brasília, v. 53, n. 1.

Brito, L. da S. y Barbosa, A(2017). Programa de auxílio moradia em uma unidade acadêmica de uma universidade de Pernambuco: uma avaliação na perspectiva dos discentes beneficiados. Revista online de Política e Gestão Educacional, v. 21 n.1, p. 125-145.

Carvalho, S. C. da S.(2013). Avaliação da eficácia da Política Pública de Assistência Estudantil na Universidade Federal de Lavras. Lavras: UFLA, 2013.130 p.

Colares, M. L. I. S.(2005). As Políticas Educacionais da Secretaria Municipal de Santarém (1989-2002). 2005. 183 p. Tese (Doutorado) Faculdade de Educação, Unicamp, Campinas, 2005.

Costa, F. L. y Castanhar, J. C.(2003). Avaliação de programas públicos: desafios conceituais e metodológicos. Revista de Administração Pública, Rio de Janeiro, v. 37, n. 5, p. 962-969.

Fernandes, R. G. y Laurades, J. B.(2016) Estudos dos fatores de evasão escolar do curso Técnico em Enfermagem do Instituto Federal do Norte de Minas Gerais. Revista Trabalho e Educação, Belo Horizonte, v. 25, n.1. p. 17-33. Disponível em: <https://seer.ufmg.br/index.php/trabedu/article/view/7865>. Acesso em: 15 ago. 2018.

Gujarati, D. N. y Porter, D. C.(2011). Econometria básica. 5. ed. Porto Alegre: AMGH.

Ifnmg - Instituto Federal De Educação, Ciência E Tecnologia Do Norte De Minas Gerais. Relatório de Gestão do Exercício de 2015. (2016). Disponível em: <http://www.ifnmg.edu.br/acessoainformacao/auditorias>. Acesso em: 15 nov.2018.

Ifnmg - Instituto Federal De Educação, Ciência E Tecnologia Do Norte De Minas Gerais. Relatório de Gestão do Exercício de 2016. (2017). Disponível em: <http://www.ifnmg.edu.br/acessoainformacao/auditorias>. Acesso em: 15 nov. 2018.

Ifnmg - Instituto Federal De Educação, Ciência E Tecnologia Do Norte De Minas Gerais _.Plano de Desenvolvimento Institucional 2014-2018. (2018). Disponível em: <http://www.ifnmg.edu.br/arquivos/2014/PDI\%202014-2018\%2009-12-13.pdf>. Acesso em: 07 jun. 2016.

Jannuzzi, P. de M. (2005). Indicadores para diagnóstico, monitoramento e avaliação de programas sociais no Brasil. Revista do Serviço Público, Brasília, v. 56, n. 2, p. 137-160 Abr/Jun. Disponível em: <https://revista.enap.gov.br/index.php/RSP/article/view/222/227>. Acesso em: 16 set. 2018. 
Jardim, A. C. G. de S. (2015). Análise dos motivos que levaram à evasão discente dos cursos Profuncionários do polo sede de Teófilo Otoni/MG, da rede e-Tec do IFNMG. 190 f. Dissertação (Mestrado Profissional) Universidade Federal dos Vales do Jequitinhonha e Mucuri Teófilo Otoni, 2015.

Magalhães, E. C. L. C..(2015). Trajetória Escolar: Memórias, Razões e Intervenientes. O curso PROEJAdo IFNMG - Campus Januária: Um estudo de caso. Florianópolis, SC, 2015. 206 p. Dissertação (Mestrado) Universidade Federal de Santa Catarina, Florianópolis.

Queiroz, B. T. M. de(2015). O Programa de Assistência e Apoio aos alunos em situação de vulnerabilidade socioeconômica do IFNMG - Campus Almenara: um estudo sobre a Educação Profissional Técnica de nível médio. 119 p. Dissertação (Mestrado Profissional - Programa de Pós-Graduação em Gestão de Instituições Educacionais) - Faculdade Interdisciplinar em Humanidades, Universidade Federal dos Vales do Jequitinhonha e Mucuri, 2015. Disponível em:

<http://media.ufvjm.edu.br/content/uploads/sites/97/2017/07/Disserta\%C3\%A7\%C3\%A3o-BrunaTatianne-Moura-De-Queir\%C3\%B3s.pdf>. Acesso em: 10 ago. 2018.

Recktenvald, M.; Mattei, L. y Pereira, V. A.(2018). Avaliando o Programa Nacional de Assistência Estudantil (PNAES) sob a ótica das epistemologias. Revista Avaliação, Campinas, v. 23, n. 02, p. 405-423. Disponível em: <http://www.scielo.br/scielo. php?pid=S1414-40772018000200405\&script=sci_abstract\&tlng=pt>. Acesso em: 15 ago. 2018.

Rocha, J. A. O.(2001). Gestão Pública e Modernização Administrativa. Oeiras: Instituto Nacional Administração, $203 \mathrm{p}$.

Rosa, A. C. F.; Amorim, J. M.; Macedo, L. F. L. (2015). Contextualização do instituto federal do Tocantins na esfera das políticas de Educação Profissional e Tecnológica. Revista de Gestão e Avaliação Educacional, Santa Maria, v. 4, n. 7, p. 113-126. Disponível em: <://periodicos.ufsm.br/regae/article/view/15086>. Acesso em: 15 ago. 2018.

Silva, I. M. de A. da y Dore, R. (2016). A evasão de estudantes com deficiência na rede federal de educação profissional em Minas Gerais. Revista Educação Especial, Santa Maria, v. 29, n. 54, p. 203-214. Disponível em: http://www.ufsm.br/revistaeducacaoespecial. Acesso em: 15/08/2018.

Souza, L. G. de (2013). Avaliação pública de políticas educacionais: concepções e práticas avaliativas dos organismos internacionais no Brasil. 170 f. il. Tese (Doutorado) - Faculdade de Educação, Universidade Federal da Bahia, Salvador, 2013. Disponível em: <https://repositorio.ufba.br/ri/bitstream/ri/17308/1/Tese\%20Lanara\%20Souza.pdf>. Acesso em: 12 dez. 2017.

Terra, V. F. (2015). Implementação da política de assistência estudantil: um estudo de três instituições federais de ensino superior localizadas no Sul de Minas Gerais. Dissertação (Mestrado Profissional). Universidade Federal de Lavras, 202 p. Disponível em: <http://repositorio.ufla.br/bitstream/1/9341/2/DISSERTACAO_Implementa\%C3\%A7\%C3\%A30\%20da\%20p ol\%C3\%ADtica\%20de\%20assist\%C3\%AAncia\%20estudantil.pdf>. Acesso em: 08 ago. 2018.

Veloso, T. C. M. A. y Silva, M. das G. M. da (2016). Avaliação de programas de expansão e ingresso nas universidades federais e os reflexos na permanência do estudante. Educação em Debate, Fortaleza, anos 35-38 - nos. 66-71. Disponível em: < http://www.periodicosfaced.ufc.br/index. php/educacaoemdebate/article/view/74>. Acesso em: 15 ago. 2018.

Esta obra está bajo una Licencia Creative Commons Attribución-NoCommercial 4.0 International

\section{(cc) EY-NC}

